\title{
Silence is Golden, Especially When You Need to Say Something Important
}

\author{
COMMUNICATION CORNER No. 12
}

\author{
by Philip Yaffe
}

\section{Editor's Introduction}

Each "Communication Corner" essay is self-contained; however, they build on each other. For best results, before reading this essay and doing the exercise, go to the first essay "How an Ugly Duckling Became a Swan," then read each succeeding essay.

How well you speak will always be an indicator of how well you know the subject at hand. And while nerves can often lead novice speakers to resort to distracting sounds and placeholders, a second or two of silence will help focus you as well as your audience. In this installment, Philip Yaffe reminds us that silence is golden. 


\title{
Silence is Golden, Especially When You Need to Say Something Important
}

\author{
COMMUNICATION CORNER No. 12
}

\section{by Philip Yaffe}

One of the absolute, unmistakable characteristics of inexperienced speakers is their incessant use of uh, um, er, ah, like, you know, and other distracting sounds, particularly at the start of each new sentence.

Novice speakers employ these unnecessary noises seemingly because they dread the "sound of silence." It's as if someone told them public speaking means that something must always be coming out of their mouth, at all times, under all conditions, no matter what.

This idea is incorrect; moreover, it is counterproductive. As professional speakers know, silence is a natural and necessary part of any good presentation.

The most common justification for all this grunting and groaning is, "I'm not always certain of the next thing to say, so I need time to think of it."

In reality, these unnecessary noises hinder thinking rather than helping it. Instead of allowing you to fully concentrate on your mental search, your lungs, larynx, and mouth are engaged in useless activity. Because they are audible, your ears are also engaged in useless activity.

It may be argued these unnecessary noises are only minor distractions, which is true. However, they are distractions. Eliminating them in favor of a second or two of silence will help focus your attention.

A second or two of silence will also help focus the attention of your audience. No matter how interesting, pertinent, and well organized your presentation, listeners occasionally need a moment's break in order to better absorb and assimilate what you have been saying. Silence provides these crucial respites.

Using silence instead of noise while you are thinking confers another important benefit. It gives the impression that you are careful and conscientious, i.e. you are fully in control of your 
subject matter. This, of course, is precisely what you want. It is also precisely what your audience wants. After all, they have spent time and energy to come hear what you have to say, so they want to be reassured that it was worth the effort. The more you appear to be in control, the happier they are.

Far from helping your presentation, uh, um, er, ah, and other unnecessary noises are detrimental to it and must be eliminated. This may seem a daunting task. However, it is easier than you might imagine.

If you now agree that these unnecessary noises impede thinking rather than aiding it, you have already taken the first crucial step. If you also agree that silence benefits your presentation rather than damaging it, you have already taken the second crucial step.

It is now only necessary to apply this knowledge.

The next time you give a presentation, consciously concentrate on avoiding these detrimental noises by putting silences in their place. At first this may feel strange; however once you experience how silences help your thinking and impress your audience, the strangeness will quickly disappear. Using helpful silences rather than destructive noises will rapidly become natural and automatic.

The speed at which this changeover takes place can sometimes be startling, virtually from one day to the next.

To help you with the transition, let's look at the opening lines of perhaps the single most recognized speech in English literature, perhaps even world literature: the Marc Antony soliloquy from Shakespeare's "Julius Caesar."

Any good piece of oratory has silences naturally built into it, as indicated by commas, periods, semi-colons, colons, and other forms of punctuation. We do not normally notice them. And if we do, we usually call them "pauses" rather than silences. However, they amount to the same thing.

We are going to examine the Marc Antony soliloquy under three conditions:

1. First, with virtually all silences replaced by the unnecessary noise "uh."

2. Second, with only the silences at the beginning of each sentence replaced by "uh."

3. Finally, as Shakespeare wrote it. 
Read each version aloud and listen to how they sound; then compare the three versions. You will be startled by the results.

\section{Natural silences replaced by "uh."}

Uh, friends, Romans, countrymen, uh, lend me your ears. Uh, I come to bury Caesar, uh, not to praise him. Uh, the evil that men do lives after them. Uh, the good, uh, is oft, uh, interred with their bones. Uh, so let it be with Caesar

The noble Brutus hath told you Caesar was, uh, ambitious. If it were so it, uh, was a grievous fault and, uh, grievously hath Caesar, uh, answer'd it.

\section{Natural silences at beginning of sentences replaced by "uh."}

Uh, friends, Romans, countrymen, lend me your ears. Uh, I come to bury Caesar, not to praise him. Uh, the evil that men do lives after them; uh, the good is oft interred with their bones. Uh, so let it be with Caesar.

Uh, the noble Brutus hath told you Caesar was ambitious. Uh, if it were so it was a grievous fault and grievously hath Caesar answer'd it.

Shakespeare was not only a master of grammar, vocabulary, syntax, sentence structure, etc., he was a master of rhythm. Here is the soliloquy exactly as he wrote it, with all the punctuations in place to guide the speaker in the proper way of delivering it.

\section{As Shakespeare wrote it.}

Friends, Romans, countrymen, lend me your ears. I come to bury Caesar, not to praise him. The evil that men do lives after them; the good is oft interred with their bones. So let it be with Caesar.

The noble Brutus hath told you Caesar was ambitious. If it were so, it was a grievous fault. And grievously hath Caesar answer'd it.

Here, under leave of Brutus and the rest-for Brutus is an honorable man; so are they all, all honorable men-come I to speak in Caesar's funeral. He was my friend, faithful and just to me. But Brutus says he was ambitious, and Brutus is an honorable man. 
None of us is ever likely to achieve the mastery of Shakespeare. But we can certainly benefit from the secret that he, and every other competent dramatist, actor, and speaker has discovered. Silence is indeed golden. Use it to enrich your presentations.

\section{Mathematical Magic}

Writing and speaking clearly and concisely is a leitmotiv of the "Communication Corner." Earlier in the series, I put myself to the test by writing instructions for two self-working card tricks and an algebraic "proof" that $2=1$ without supporting diagrams or photos.

Here is the description of an intriguing mathematical puzzle, its conventional solution, and an artful alternative. Although a somewhat different writing challenge, the objective is the same. And so is the guiding principle. In the words of Robert Louis Stevenson, author of Kidnapped, Treasure Island, and The Strange Case of Dr. Jekyll and Mr. Hyde: "Don't write merely to be understood. Write so that you cannot possibly be misunderstood."

If you can achieve this, you can write anything-and say anything in a speech to the plaudits of you audience.

Many years ago one of my favorite science magazines published a puzzle, which at first glance seemed quite disjointed. The following month it published the solution to the puzzle, which made complete sense.

I remember this particular puzzle not only because it was so clever in itself, but because of an interesting follow-up to it by one of the magazine's readers.

In this installment of "Communication Corner," you will find the original puzzle. In the next installment, you will find the magazine's solution plus the follow-up.

Here is the puzzle: A hunter leaves his cabin. He walks exactly 1 kilometer due south, then turns and walks exactly $1 \mathrm{~km}$ due east. He shoots a bear, which he drags exactly I km back to his cabin. What color is the bear?

As with the apparent algebraic proof that $2=1$ (see Communication Corner No. 8), some people are likely to figure out the solution to this conundrum almost immediately, while others probably never will. However, I would wager that few would come up with the striking followup to the solution. 


\section{HOMEWORK: Retrospective to Communication Corner No. 11}

In the previous installment, you were asked to read a summary of everything you had already learned about expository (non-fiction) writing in the first nine essays in the Communication Corner series, and to fix all the key ideas firmly in mind. You were also asked to think about how the principles and practices of good writing might also be applied to giving a good speech or other types of oral presentations.

If you haven't already done so, please do so now. Understanding these key principles and practices will be crucial for fully benefiting from all the Communication Corner essays to follow.

\section{CURRENT HOMEWORK}

As noted in the previous installment, if conciseness is critical in writing, it is even more so (if that's possible) in speaking.

When you speak, your words flow over the listeners like a cloud. First they are there, then they are gone. If the listeners don't immediately grasp what you are saying, they have no opportunity to go back over a sentence to try to divine its meaning. Therefore, everything you say needs to advance your meaning. Using unnecessary words or using ambiguous words and phrases virtually ensures listeners will not fully grasp your message.

You were given a few exercises to hone your conciseness skills in both writing and speaking. Remember the definition of conciseness: As long as necessary; as short as possible (Co $=\mathrm{LS}$ ).

Each exercise had two texts labeled "Original" and "Analysis." The procedure for doing the exercises was:

1. Cover the page so that only the Original is visible and read the text.

2. As you read, and with everything else still covered, make notes about what you think needs to be done to improve the Original.

3. Uncover the Analysis and compare it with your notes.

4. Rewrite the text.

In this installment, you will be able to compare your revision of the text with my revised version. Remember: There is always more than one way of writing and saying things well. So if your revision doesn't match mine, don't be concerned. The important thing is that it is concise, i.e. as long as necessary: as short as possible (Co $=\mathrm{LS})$. 


\section{Exercise 1}

[Original]

During employment with $A B C$ Corporation, employees are legally entitled to take leave from the office during normal working hours. When this leave is taken, employees continue to receive their normal salary.

[Analysis]

During employment with $A B C$ Corporation [Unnecessary words], employees are legally entitled to take leave from work during normal working hours [Unnecessary words]. When this leave is taken [Unnecessary words], employees continue to receive their normal salary.

[Revision]

ABC Corporation employees are legally entitled to take leave from work while continuing to receive their normal salary.

\section{Exercise 2}

[Original]

Annual leave entitlements are generated in accordance with legal requirements. Employees are credited with their annual leave entitlement during the working year and entitled to access this balance as from January 1 of the following year.

[Analysis]

Annual leave entitlements are generated in accordance with legal requirements [ $\boldsymbol{s}$ this sentence necessary?]. Employees are credited with their annual leave entitlement during the working year and entitled to access this balance as from January 1 of the following year [Not clear; be more explicit].

[Revision]

Employees generate annual leave entitlement during the working year for use during the following year, starting from January 1. Example: Leave entitlement generated during 2018 may be used starting from January 1, 2019. 


\section{Exercise 3}

[Original]

An employee may accumulate annual leave beyond the legal minimum only in the following circumstances:

1. If there is written documentation proving that the employee's immediate manager has refused a leave request.

2. If there is written proof that there were special circumstances why annual leave couldn't be taken during the current year.

3. If the employee's immediate manager otherwise supports an application for additional leave.

[Analysis]

An employee may accumulate annual leave beyond the legal minimum [What is this minimum?] only in the following circumstances.

1. If there is written documentation [Use active voice] proving that the employee's immediate manager refused a leave request.

2. If there is written proof [Use active voice] that there were special circumstances why annual leave couldn't be taken during the current year.

3. If the employee's immediate manager otherwise supports an application for additional leave.

Avoid repetition of "If" at the beginning of each bullet point.

[Revision]

An employee may accumulate annual leave beyond the legal 20-day minimum only under one or more of the following circumstances.

1. Written documentation confirms that the immediate manager refused a request for leave, thus creating the need to carry some leave over to the following year.

2. Written documentation confirms that special circumstances prevented the employee from taking leave during the year it should have been taken.

3. The employee's immediate manager otherwise supports the application for leave carryover. 


\section{Exercise 4}

[Original]

BBX is an agency born with the Swedish Internet, in 1996. Established in Stockholm, it has seen rapid growth and has attained the status of a completely multi-disciplinary, integrated agency.

The skills of the agency have indeed developed rapidly. This enables it to offer an extremely wide range of services today, with the same concern for quality and professionalism. These range from interface design to brand building, from Internet strategy and loyalty magazines to training in client satisfaction, not forgetting the more classic aspects of above and below the line marketing: direct mail, address list management, media planning . . . all while keeping an important point in mind; increasing the quality of the relationship which our clients maintain with their prospects or their consumers.

[Analysis]

BBX is an agency [Unnecessary words] born with the Swedish Internet, in 1996 [Move date]. Established in Stockholm, it has seen rapid growth and has attained the status of a completely multi-disciplinary, integrated agency.

The skills of the agency have indeed developed rapidly [Is this sentence necessary?]. This enables it to offer an extremely wide range of services today, with the same [Same as what?] concern for quality and professionalism. These [Services?] range from interface design to brand building, from Internet strategy and loyalty magazines to training in client satisfaction, not forgetting the more classic aspects of above and below the line marketing: direct mail, address list management, media planning . . . all while keeping an important point in mind; increasing the quality of the relationship which our clients maintain with their prospects or their consumers. [The sentence is too complex; services not easily distinguishable. Simplify.]

[Revision]

BBX (Stockholm) was born in 1996 with the Swedish internet. A pioneer of this new medium, it underwent rapid growth, quickly becoming a full multi-disciplinary, integrated communication agency.

Today, BBX's synergistic mix of skills permit the agency to offer an exceptionally wide range of services-all with a single-minded concern for professionalism and quality:

- Interface design 
- Brand building

- Internet strategy

- Loyalty magazines

- Client satisfaction training

- Above and below the line marketing (direct mail, address list management, media planning, etc.)

These and a host of other agency services aim at a single objective: Increase the quality of the relationship our clients maintain with their clients and prospects.

\section{Current Homework}

There is no homework, other than to pay attention to how often people needlessly use these useless sounds and how annoying they can be. In the next installment (CC13), we will examine this phenomenon further, including simple suggestions on how to put an end to it.

\section{About the Author}

Philip Yaffe was born in Boston, Massachusetts, in 1942 and grew up in Los Angeles, where he graduated from the University of California with a degree in mathematics and physics. In his senior year, he was also editor-in-chief of the Daily Bruin, UCLA's daily student newspaper. He has more than 40 years of experience in journalism and international marketing communication. At various points in his career, he has been a teacher of journalism, a reporter/feature writer with The Wall Street Journal, an account executive with a major international press relations agency, European marketing communication director with two major international companies, and a founding partner of a specialized marketing communication agency in Brussels, Belgium, where he has lived since 1974. He is the author of more than 20 books, which can be found easily in Amazon Kindle.

DOI: $10.1145 / 3310318$ 